\title{
Effects of hyperkalaemia on the excitability of peripheral nerve
}

\author{
K. N. SENEVIRATNE, O. A. PEIRIS ${ }^{1}$, AND A. WEERASURIYA \\ From the Department of Physiology, Faculty of Medicine, \\ University of Ceylon, Colombo 8, Ceylon
}

SUMMARY An experimental animal model has been developed for the study of excitability change in peripheral nerve during limb ischaemia. This model has been used to investigate the effects of hyperkalaemia on the sequence of excitability change that occurs during cuff-induced limb ischaemia and in the post-ischaemic recovery period. The results lend support to the hypothesis that the dynamics of $\mathrm{K}$ ion concentration in the periaxonal space play a critical role in determining these excitability changes and that the polyanionic mucopolysaccharide gap substance of the node of Ranvier is likely to constitute the diffusion barrier that defines the periaxonal space.

The effects of ischaemia and of the subsequent re-establishment of the circulation on sensory nerves in the healthy human limb have been studied by Lewis, Pickering, and Rothschild (1931), Zotterman (1933), Kugelberg (1944, 1946), Weddell and Sinclair (1947), Merrington and Nathan (1949), Poole (1956a, b), and Seneviratne and Peiris (1968a). A consistent observation has been the occurrence of paraesthesiae during early ischaemia and in the initial stages of post-ischaemic recovery.

Seneviratne and Peiris (1968a) measured excitability changes in the sensory fibres of the human median nerve during and after a half hour period of limb ischaemia, and demonstrated a temporal coincidence of the paraesthesiae with the transient phases of hyperexcitability of the sensory nerves during the early ischaemic and post-ischaemic periods.

Steiness (1959) has drawn attention to the relative resistance of the peripheral nerve of diabetic subjects to inactivation by ischaemia and these observations have since been confirmed by Castaigne, Cathala, Dry, and Mastropaolo (1966), Gregersen (1968), and Seneviratne and Peiris (1968b). Similar changes have also been reported in uraemia (Christensen and Orskov, 1969) and chronic liver disease (Seneviratne and Peiris, 1970), these findings necessitating a clearer understanding of the

\footnotetext{
1 Present address: Southland Hospital, Invercargill, New Zealand.
}

mechanisms responsible for the changes in healthy nerve.

Seneviratne and Peiris (1969) have shown that the characteristic sequence of changes of excitability of human sensory nerves during cuff-induced limb ischaemia were essentially similar to the excitability changes observed in isolated rat sciatic nerves exposed to hypoxic gas mixtures. They have also demonstrated that the resistance of the isolated sciatic nerve of the alloxan diabetic rat to hypoxia in vitro was very similar to the resistance of the peripheral nerve of the diabetic subject to inactivation by ischaemia (Seneviratne and Peiris, 1969).

The effects of insulin on the isolated rat sciatic nerve have shown that pretreatment of rats with insulin increases significantly the rate of change of excitability of the isolated nerves in hypoxic gas mixtures, and these studies have led Seneviratne and Peiris (1970a) to postulate that these excitability changes were due to the progressive depolarization of the axons produced by an accumulation of $\mathrm{K}^{\prime}$ in a periaxonal space. Hypoxia leads to an efflux of $\mathrm{K}^{\prime}$ from the intracellular compartment, a process accelerated by treatment with insulin. It is envisaged that this $\mathrm{K}^{\prime}$ is held up against the axonal surface by a diffusion barrier, which in the healthy state serves to limit the rate at which the $\mathrm{K}^{\prime}$ ion is allowed to diffuse away from the axonal surface into the endoneurial spaces of the nerve trunk. Since this hypothesis relates the rate of change of 
nerve excitability during ischaemic and hypoxic conditions to the dynamics of $\mathrm{K}^{\prime}$ equilibrium within a periaxonal space, it predicts that an increased input of $\mathrm{K}^{\prime}$ into the space from the circulating blood should produce an initial increase of excitability of the nerve fibre, and that limb ischaemia during hyperkalaemic conditions should produce a more rapid inactivation of the nerve, and a more delayed recovery during vascular restitution.

Simpson (1962) drew attention to the importance of the micro-environment of the axons within the nerve sheath. He recognized that the relative constancy of this environment was essential for the normal functioning of nerve, and that this was maintained despite wide fluctuations in plasma constitution by the slow rate of equilibration across the sheath. His results showed that 'depression of conduction velocity was more closely related to disorders of the myelin than to neuronal electrolyte disturbances' and suggested that 'one or other of the axone coverings may have a direct effect on the excitable membrane of the nerve fibre by affecting the rate of transmembranal exchange of electrolytes'.

Although hypoxia of the isolated nerve in vitro reproduces the effects of limb ischaemia in vivo, the value of this experimental preparation is limited by the fact that it cannot be used to study the excitability changes associated with recovery. Observations on human subjects, however, have obvious limitations in that the extent of experimental variation of the ionic environment is restricted. The experiments described below were designed to develop a suitable experimental model for the study of the effects of changes of the ionic environment on peripheral nerve excitability during and after limb ischaemia. This model has also been used to test the validity of the hypothesis that changes of peripheral nerve excitability are determined by the dynamics of $\mathrm{K}^{\prime}$ equilibrium in the periaxonal space.

\section{METHODS}

Twenty four cats weighing 2 to $3 \mathrm{~kg}$ each were used in these experiments. They were anaesthetized with sodium pentobarbitone (Nembutal) given intramuscularly in a dose of $50 \mathrm{mg} / \mathrm{kg}$ body weight. The animal was placed in the supine position on a board and its limbs were firmly fixed to the board by rubber bands. Due to the high electrical impedance of the skin, subcutaneous electrodes were used for stimula- ting and recording. The stimulating electrodes we a pair of silver clips, $0.4 \mathrm{~cm}$ broad at the point contact, which gripped the subcutaneous tissue. The anode was placed just proximal to the hallux, the cathode being $1 \mathrm{~cm}$ proximal to the anode. The nerve was excited by means of cathodal stimulatiof Square wave stimuli from a Grass S4 stimulator we? delivered through a Grass SIU4 RF couple isolating transformer. The recording electrodes we a pair of silver alloy needles $2.5 \mathrm{~cm}$ long and $1 \mathrm{~mm}$ broad attached to a flexible plastic mount. Tife needles were inserted subcutaneously $1 \mathrm{~cm}$ aparif, between the tendo calcaneus and the tibialis neri away from the muscle bellies of the neighbouring muscles. The earthed plastic mount carrying the recording needles was fixed firmly by an elastic strof round the leg. A silver clip connected to earth was placed subcutaneously between the stimulating and recording electrodes. The evoked potentials weEt amplified by a Grass P511R RC coupled pre amplifier with its low frequency filter set at $1.5 \sqrt{\mathrm{H}}$ and the high frequency filter set at $10 \mathrm{kHz}$. The amplified responses were monitored through a lou ợ speaker and displayed on one beam of a Tektronf 502 oscilloscope. The sweep of the oscilloscope ant the stimulator were synchronized with the shutter of the Nihon-Koden camera mounted on the oscilloscope. The lower beam of the oscilloscope monitored the stimulus through a $10 \mathrm{M} \Omega$ probe. All experimen were done in a room maintained at $27^{\circ} \mathrm{C}$. Great are was taken to prevent changes in the relative positi画 of the electrodes during inflation and deflation $\$ \varphi$ the cuff producing vascular occlusion.

EXPERIMENT I In five cats the responses to a supro maximal stimulus were observed on the oscilloscop: screen and the stimulus strength reduced until th evoked response was $50 \%$ of its maximum size. The stimulus intensity was maintained at this strengt and the responses to it were recorded at five minute intervals for a period of 60 minutes.

EXPERIMENT II In 15 cats the stimulus strength was adjusted to give a response approximately $50 \%$ of that obtained with a supramaximal stimulus. Vasctin. lar occlusion of the limb was obtained by a sphygmof manometer cuff (bag size $7.5 \mathrm{~cm}$ by $4 \mathrm{~cm}$ wide? applied to the upper part of the thigh. The cuff was inflated to a pressure of $200 \mathrm{~mm} \mathrm{Hg}$. Records of the response to the submaximal stimulus were made a two minute intervals until the response was abot ished, at which time the cuff was released and the recordings of evoked responses continued for period of 30 minutes after vascular restitution.

EXPERIMENT III In 10 cats a $10 \%$ solution of Kद্d (2.0 $\mathrm{mM} / \mathrm{kg}$ body weight) was injected intr官 peritoneally and the response to a submaxima stimulus of constant strength recorded at fiver 
minute intervals for 60 minutes. In this, and all subsequent experiments where intraperitoneal $\mathrm{KCl}$ was used, blood serum $\mathrm{K}$ levels were estimated before the injection of the $\mathrm{KCl}$ solution and at 10 minute intervals thereafter. During this period a bipolar limb lead ECG was monitored continuously.

EXPERIMENT IV In five cats experiment III was repeated using $\mathrm{NaCl}$ instead of $\mathrm{KCl}$. A $10 \%$ solution of $\mathrm{NaCl}$ was injected intraperitoneally at a dosage of $2.0 \mathrm{mM} / \mathrm{kg}$ body weight.

EXPERIMENT $v$ In five cats the changes in response amplitude produced by stimuli of increasing voltage were recorded. The cats were then made hyperkalaemic as described in experiment III. Sixty minutes after the injection of $\mathrm{KCl}$ the responses to stimuli of increasing voltage were recorded.

EXPERIMENT VI In 10 cats 60 minutes after the standard dose of $\mathrm{KCl}$ had been injected intraperitoneally, one of the hind limbs was subjected to ischaemia and recovery. The ECG was monitored continuously to indicate the effect of hyperkalaemia on the cardiac rhythm. The experiments in which a gross cardiac arhythmia occurred were discontinued. The submaximal stimulus employed produced a response which was approximately $50 \%$ of the maximum evoked response. The sphygmomanometer cuff was applied and records of the evoked response were taken at regular intervals until the response was abolished at which time the cuff was released and the responses recorded for another 30 minutes. These experiments were done on 10 of the cats used in the control experiment (experiment II). All experiments were done at least 10 days after experiment II and ischaemia was induced in the limbs that were not subjected to ischaemia in experiment II.

\section{RESULTS}

EXPERIMENT I In all five experiments, the response amplitude tended to decrease slowly with time, the maximum decrease observed during the 60 minute period being $9 \%$ of the resting value.

EXPERIMENT II The results of one such experiment are represented in Fig. 1, and graphically in Fig. 2. The response grows in size during the first 10 minutes of ischaemia and then decreases rapidly, being abolished in 20 to 30 minutes. With release of cuff the response grows rapidly in size during the first five minutes of vascular restitution. An analysis of the results obtained in these 15 experiments is presented in the Table.

EXPERIMENT III In all the experiments of this series in which the effects of hyperkalaemia on the resting excitability of nerve was studied, the evoked response amplitudes tended to increase

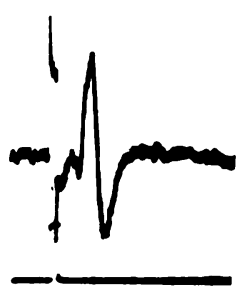

0

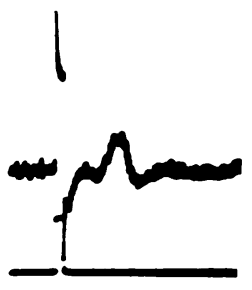

1

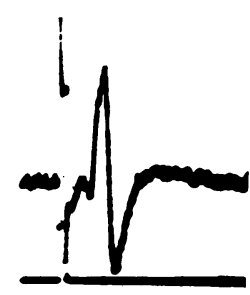

6

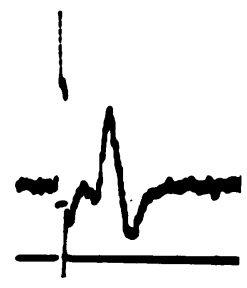

2
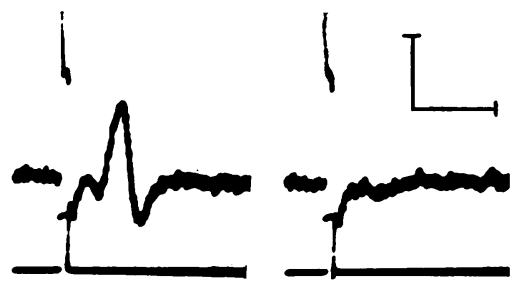

22

30

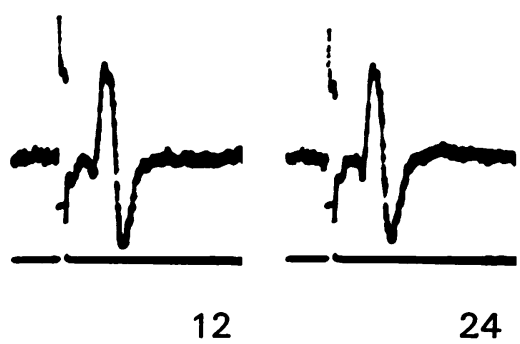

FIG. 1. Effects of limb ischaemia on the compound action potential evoked by a submaximal stimulus of constant size in a control cat. Upper row: during ischaemia. Lower row: post-ischaemic recovery. Numerals denote time in minutes. Calibration 1 msec and $25 \mu \mathrm{V}$. 
TABLE

RESULTS FROM 15 CONTROL AND 10 HYPERKALAEMIC CATS

\begin{tabular}{|c|c|c|c|}
\hline & $\begin{array}{c}\text { Control } \\
\text { cats }\end{array}$ & $\begin{array}{c}\text { Hyper- } \\
\text { kalaemic } \\
\text { cats }\end{array}$ & $\begin{array}{l}\text { Significance } \\
\text { (Student } \\
\text { 't' test) }\end{array}$ \\
\hline 1. Mean maximum ampli- & $\begin{array}{c}115 \% \\
(103-135)\end{array}$ & $\begin{array}{c}103 \cdot 2 \% \\
(101-112)\end{array}$ & $P<0.002$ \\
\hline $\begin{array}{l}\text { 2. Mean time taken to reach } \\
\text { maximum amplitude } \\
\text { during ischaemia and } \\
\text { range of variation }\end{array}$ & $\underset{(5-12)}{7 \cdot 1 \min }$ & $\begin{array}{c}3.4 \mathrm{~min} \\
(1-6)\end{array}$ & $P<0.01$ \\
\hline $\begin{array}{l}\text { 3. Mean ischaemic inactiva- } \\
\text { tion time and range of } \\
\text { variation }\end{array}$ & $\begin{array}{c}30 \cdot 6 \mathrm{~min} \\
(27-37)\end{array}$ & $\begin{array}{c}25.9 \mathrm{~min} \\
(21-31)\end{array}$ & $P<0.05$ \\
\hline $\begin{array}{l}\text { 4. Mean amplitude } 1 \text { minute } \\
\text { after cuff release and range } \\
\text { of variation }\end{array}$ & $\begin{array}{c}56 \cdot 0 \% \\
(34-79)\end{array}$ & $\begin{array}{l}32.9 \% \\
(23-40)\end{array}$ & $P<0.001$ \\
\hline $\begin{array}{l}\text { 5. Mean amplitude } 2 \text { minutes } \\
\text { after cuff release and }\end{array}$ & $\begin{array}{c}74 \cdot 5 \% \\
(57-113)\end{array}$ & $\begin{array}{l}43 \cdot 4 \% \\
(36-53)\end{array}$ & $P<0.001$ \\
\hline $\begin{array}{l}\text { 6. Mean serum K level at } \\
\text { commencement of } \\
\text { ischaemia (m-equiv/1.) }\end{array}$ & $\begin{array}{c}4 \cdot 4 \\
(4 \cdot 2-4 \cdot 7)\end{array}$ & $\begin{array}{c}6 \cdot 6 \\
(5 \cdot 8-8 \cdot 2)\end{array}$ & $P<0.001$ \\
\hline
\end{tabular}

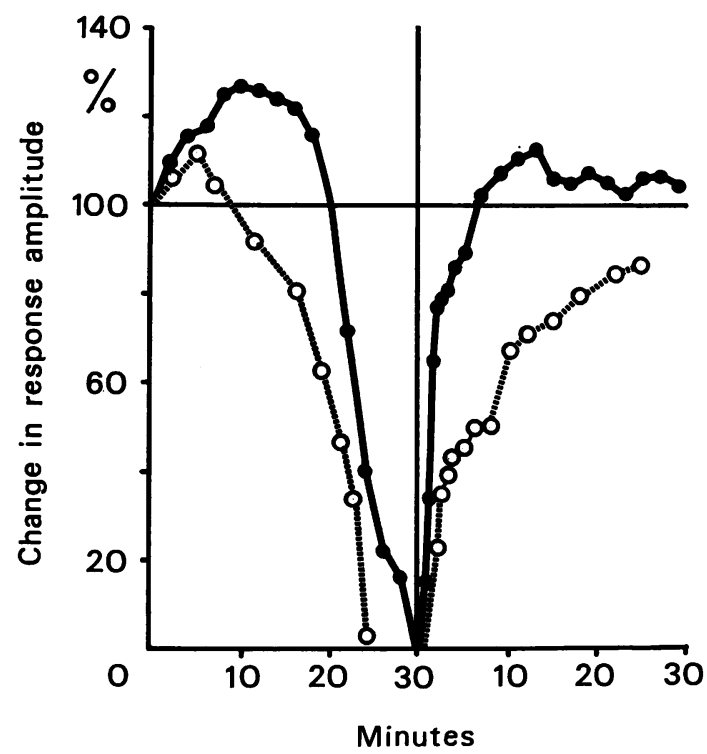

FIG. 2. Percentage changes of response amplitude evoked by a submaximal stimulus of constant size, during and after a 30 minute period of ischaemia. - Control cat. $\bigcirc$ Same cat 60 minutes after intraperitoneal injection of $\mathrm{KCl}$.

with time during the 60 minute period. The results obtained from this series are illustrated in Fig. 3.

EXPERIMENT IV When $\mathrm{NaCl}$ was used instead of $\mathrm{KCl}$ the response amplitudes tended to decrease in size, the maximum decrease being $8 \%$ of the

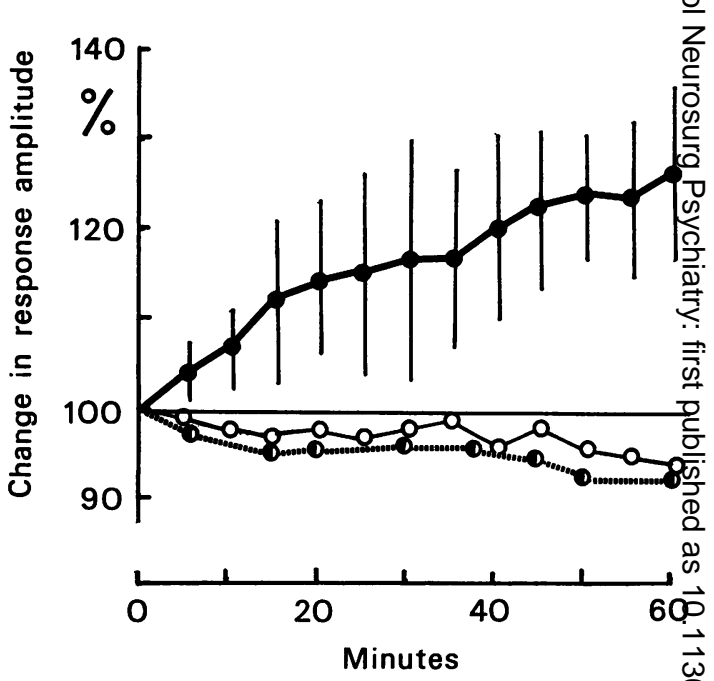

FIG. 3. Percentage changes of response amplitude. evoked by a submaximal stimulus of constant size $\bigcirc$ Control cat, mean of five experiments. Mean of five experiments in cats injected with $\mathrm{NaCl}$. Medfl with standard deviations from 10 experiments, cats injected with $\mathrm{KCl}$.

resting value. The results of these experiments are similar to those obtained from the conf animals in experiment $I$ and do not sho significant variation from them. ํㅡㄹ EXPERIMENT $v$ In the five experiments of this series the strength response curves plotted in tho hyperkalaemic state were shifted to the left of the curves obtained during the control period The results from one such experiment are illustrated in Fig. 4.

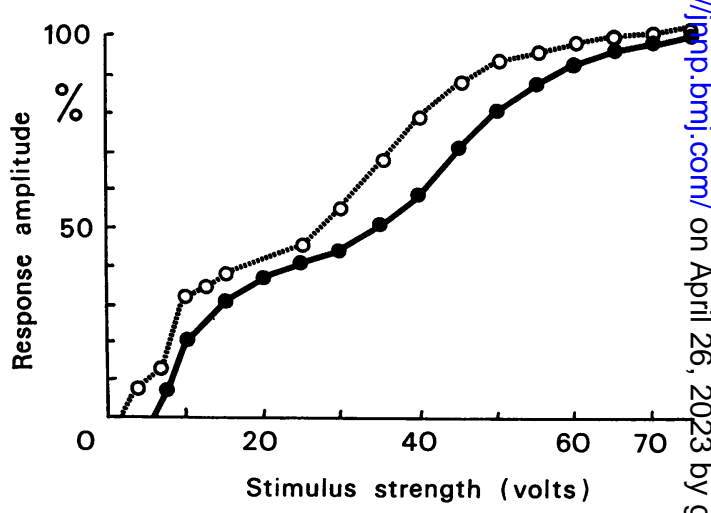

FIG. 4. Stimulus intensity-response amplitude curves from a single cat, $\bigcirc$ Control, $\bigcirc$ Sixty minute after injection of $\mathrm{KCl}$. 
EXPERIMENT VI The changes in excitability during the period of ischaemia and the period of recovery are qualitatively similar to those obtained from control animals in experiment II, but show significant differences in the rate of change of excitability in the ischaemic and postischaemic phases. The results obtained from an experimental animal where ischaemia was produced in the control and hyperkalaemic state are illustrated in Fig. 2. The results obtained from 10 cats in this series are represented in the Table and show that the hyperkalaemic cats have a significant reduction of ischaemic inactivation time and an increased duration of post-ischaemic recovery time.

\section{DISCUSSION}

The results of experiment II show that cuff induced limb ischaemia in the control cat produces a transient increase in the excitability of a group of low threshold nerve fibres before they are inactivated by ischaemia. In the postischaemic phase these fibres show once again a short period of hyperexcitability before the full recovery of function. The time course and the magnitude of excitability change seen in the cat are very similar to those observed in the median nerve of healthy human adults (Seneviratne and Peiris, 1968a). Seneviratne and Peiris (1970a) have argued that these excitability changes could be accounted for in terms of the $K$ ion concentration available at the periaxonal surface of the nerve. Thus, nerve hypoxia leads to a $\mathrm{K}$ efflux from the axon, and an increasing accumulation of surface $K$ produces a progressive depolarization of the axon. At first this leads to an increase in the excitability of the fibre as the resting membrane potential approaches critical value. Continued increase in the periaxonal $\mathrm{K}$ concentration causes further depolarization and conduction block. In the post-ischaemic phase restoration of the blood supply leads to a reactivation of the membrane $\mathrm{Na}-\mathrm{K}$ pump and an influx of $\mathrm{K}$ from the periaxonal space into the axon, the consequent reduction of the surface $K$ concentration resulting in repolarization of the fibre. Before the resting membrane potential is reached, the transit through the critical membrane voltage leads to the phase of hyperexcitability which is observed in the early postischaemic period.

The results obtained in this study lend support to the concept of a diffusion barrier and the critical role of the $\mathrm{K}$ ion. In the experiments reported earlier (Seneviratne and Peiris, 1968a; 1970a,b) limb ischaemia or nerve hypoxia was employed to produce the $\mathrm{K}$ efflux into the periaxonal space which led to the initial increase in the excitability of the axon. The results of experiments III and V show that a comparable increase in the excitability of the nerve occurs in the hyperkalaemic cat, presumably because the increased blood level of $\mathrm{K}$ serves to maintain an increased input of $\mathrm{K}$ from the blood and endoneurial space into the periaxonal space. The hyperexcitability of nerve induced by hyperkalaemia is similar to the phase of hyperexcitability which occurs early in the ischaemic process. Since this is caused by the increasing concentration of periaxonal $\mathrm{K}$, it follows that a further rise of serum $K$ should lead to the characteristic pattern of inactivation that is seen late in the ischaemic process. This degree of hyperkalaemia, however, could not be reached in the experimental animals because of the gross irregularities of cardiac function that develop at high serum $\mathrm{K}$ levels. The results of experiment IV, in which $\mathrm{NaCl}$ was used in place of $\mathrm{KCl}$, show that the excitability change occurs only with the $K$ and that this is not a non-specific electrolyte effect. In experiment VI limb ischaemia has been used in the hyperkalaemic cat to accelerate the build up of periaxonal $\mathrm{K}$ concentration by providing an additional input of $\mathrm{K}$ from axon into the space. In these conditions, it is to be expected that the rate of depolarization would be increased, leading in turn to a more rapid sequence of excitability change. The results of experiment VI depicted in Fig. 2 and the Table show a significant reduction of these parameters in the hyperkalaemic cat. These results also show a very significant increase in the post-ischaemic recovery time in the hyperkalaemic cat.

In the control cat, restoration of the circulation to the ischaemic nerve leads to the reactivation of the membrane $\mathrm{Na}-\mathrm{K}$ pump and an uptake of $\mathrm{K}$ from the periaxonal space into the axon. The periaxonal $\mathrm{K}$ concentration would be reduced further by a diffusion of $\mathrm{K}$ along a concentration gradient from the periaxonal space to the endoneurial space and blood. It is likely that the delayed recovery of the hyperkalaemic nerve is due to the raised blood $K$ level effectively reducing the rate of transfer of $K$ from periaxonal space to blood.

If surface $K$ concentrations are to play a 
critical role in the depolarization process, it is necessary to postulate the existence of a diffusion barrier which could restrict the free diffusion of ions from the axonal surface into the endoneurial spaces. Such a barrier would have to be located in very close proximity to the node of Ranvier which, in the myelinated axon, is the functional site concerned with active membrane ion exchange. This is also made necessary by the short time constant of the excitability changes associated with ischaemia and recovery. These rapid membrane potential changes require such changes of surface $K$ concentration that can be achieved only in very small volumes. Frankenhaeuser and Hodgkin (1956) have postulated the existence of a similar diffusion barrier situated about $200 \AA$ away from the squid axon to account for changes in the after potential that result from repetitive stimulation of the axon.

In their study of the node of Ranvier, Hess and Young (1952) observed the presence of a 'cementing disc' which surrounded the exposed portion of the axon at the node. Staining of the disc with silver nitrate and methylene blue made them recognize that the "colouration is due to active ionic interchange perhaps with a high concentration of chloride and potassium ions', that the composition of the disc must have some effect on the passage of ions from the axon surface to the perinodal space, and that 'free diffusion between nodal axon and external environment could not be assumed until the permeability properties of the cementing disc and perinodal space were known'. Recent studies have drawn attention to the affinity of the cementing disc for a wide variety of metallic cations, and Abood and Abul-Haj (1956) have demonstrated that the ion binding capacity of the nodal gap was due to a local concentration of non-sulphated mucopolysaccharides. Langley (1969) and Landon and Langley (1969, 1971) using histochemical techniques demonstrated the presence of a fixed anionic charged matrix surrounding the axon at the node. This nodal gap substance is shown to be capable of binding the ferric, barium, cupric, lanthanum, sodium, and potassium ions. These authors suggest that the cation-matrix polyanion bond is a reversible electrostatic one, and that the greater part of the cation binding property is due to the presence of carboxylated polyanions in the nodal matrix. Landon and Langley (1971) state that 'monovalent cations such as the sodium ion, with a large hydrated ionic radius whilst being bound in the sense of satisfying the condition of electro- $\bar{q}$ neutrality can probably move with relative free- $\bar{c}$ dom within the polyanion atmosphere and be readily exchangeable for other ions added to the matrix', and that 'the presence of such a matrix might limit the diffusion of the potassium ion and hold it available for redistribution across the nodal axolemma'.

These studies on the nodal gap substance of $\overrightarrow{\vec{F}}$ myelinated nerve fibres provide very strong evi $-\frac{0}{0}$ dence in favour of the existence of a diffusion barrier. The physico-chemical properties of this $\overline{\overline{\bar{s}}}$. barrier fit the requirements which an effective $\frac{\mathbb{Q}}{\Omega}$ functional barrier must possess if it is to accounto for the excitability changes which have been $\vec{\circ}$ observed in healthy human and rat nerve (Seneviratne and Peiris, 1968a, 1969, 1970a).

The results also draw attention to the ionico environment of the axon within the nerve trunk. There is good evidence that the perineuriumw serves to isolate the axons from the generali extracellular fluid pool of the body (Krnjevic, $\vec{A}_{\triangle}$ 1954; Waggener, Bunn, and Beggs, 1965; Shantha and Bourne, 1968; Olsson and Reese,. 1971), maintaining the axons within a specta $I_{\triangle}$ endoneurial micro-environment the integrity offo. which is further defended by the restrict permeability of the endoneurial capillary (Olss 1966). The periaxonal diffusion barrier described above would maintain an even more circum-o scribed ionic environment around the individual node, separate even from the micro environment of the endoneurial space.

\section{REFERENCES}

Abood, L. G., and Abul-Haj, S. K. (1956). Histochemistry and characterization of hyaluronic acid in axons of peripheral nerve. Journal of Neurochemistry, 1, 119-125. Castaigne, P., Cathala, H.-P., Dry, J., and Mastropaolo, C. (1966). Les réponses des nerfs et des muscles à dę̧ stimulations électriques au cours d'une épreuve de garro ischémique chez l'homme normal et chez le diabétique? Revue Neurologique, 115, 61-66.

Christensen, N. J., and Ørskov, H. (1969). Vibratory per ception during ischaemia in uraemic patients and in subjects with mild carbohydrate intolerance. Journal of Neuro옥 logy, Neurosurgery, and Psychiatry, 32, 519-524.

Frankenhaeuser, B., and Hodgkin, A. L. (1956). The aftero effects of impulses in the giant nerve fibres of Loligo Journal of Physiology, 131, 341-376.

Hess, A., and Young, J. Z. (1952). The nodes of Ranvier? Proceedings of the Royal Society of London B, 140, 301-320N

Krnjević, K. (1954). Some observations on perfused frog sciatic nerves. Journal of Physiology, 123, 338-356.

Kugelberg, E. (1944). Accommodation in human nerves?

Acta Physiologica Scandinavica, 8, Suppl. 24 .
Kugelberg, E. (1946). 'Injury activity' and 'trigger zones' if human nerves. Brain, 69, 310-324.

Landon, D. N., and Langley, O. K. (1969). Cationic binding at the node of Ranvier. Journal of Anatomy, 105, 196. 
Landon, D. N., and Langley, O. K. (1971). The local chemical environment of nodes of Ranvier: a study of cation binding. Journal of Anatomy, 108, 419-432.

Langley, O. K. (1969). Ion-exchange at the node of Ranvier, Histochemical Journal, 1, 295-309.

Lewis, T., Pickering, G. W., and Rothschild, P. (1931). Centripetal paralysis arising out of arrested bloodflow to the limb, including notes on a form of tingling. Heart, 16, 1-32.

Merrington, W. R., and Nathan, P. W. (1949). A study of post-ischaemic paraesthesiae. Journal of Neurology, Neurosurgery, and Psychiatry, 12, 1-18.

Olsson, Y. (1966). Studies on vascular permeability in peripheral nerves. I. Distribution of circulating fluorescent serum albumin in normal, crushed and sectioned rat sciatic nerve. Acta Neuropathologica, 7, 1-15.

Olsson, Y., and Reese, T. S. (1971). Permeability of vasa nervorum and perineurium in mouse sciatic nerve studied by fluorescence and electron microscopy. Journal of Neuropathology and Experimental Neurology, 30, 105-119.

Poole, E. W. (1956a). Ischaemic and post-ischaemic paraesthesiae. Normal responses in the upper limb with special reference to the effect of age. Journal of Neurology, Neurosurgery, and Psychiatry, 19, 148-154.

Poole, E. W. (1956b). Ischaemic and post-ischaemic paraesthesiae in polyneuritis. Journal of Neurology, Neurosurgery, and Psychiatry, 19, 281-288.

Seneviratne, K. N., and Peiris, O. A. (1968a). The effect of ischaemia on the excitability of human sensory nerve. Journal of Neurology, Neurosurgery, and Psychiatry, 31, 338-347.

Seneviratne, K. N., and Peiris, O. A. (1968b). The effect of ischaemia on the excitability of sensory nerves in diabetes mellitus. Journal of Neurology, Neurosurgery, and Psychiatry, 31, 348-353.

Seneviratne, K. N., and Peiris, O. A. (1969). The effects of hypoxia on the excitability of the isolated peripheral nerves of alloxan diabetic rats. Journal of Neurology, Neurosurgery, and Psychiatry, 32, 462-469.

Seneviratne, K. N., and Peiris, O. A. (1970a). The role of diffusion barriers in determining the excitability of peripheral nerve. Journal of Neurology, Neurosurgery, and Psychiatry, 33, 310-318.

Seneviratne, K. N., and Peiris, O. A. (1970b). Peripheral nerve function in chronic liver disease. Journal of Neurology, Neurosurgery, and Psychiatry, 33, 609-614.

Shantha, T. R., and Bourne, G. H. (1968). The perineural epithelium-a new concept. In The Structure and Function of Nervous Tissue. Vol. 1, pp. 379-459. Edited by G. H. Bourne. Academic Press: New York.

Simpson, J. A. (1962). Conduction velocity of peripheral nerves in human metabolic disorders. Electroencephalography and Clinical Neurophysiology, Suppl. 22, 36-43.

Steiness, I. (1959). Vibratory perception in diabetics during arrested blood flow to the limb. Acta Medica Scandinavica, 163, 195-205.

Waggener, J. D., Bunn, S. M., and Beggs, J. (1965). The diffusion of ferritin within the peripheral nerve sheath: an electron microscopy study. Journal of Neuropathology and Experimental Neurology, 24, 430-443.

Weddell, G., and Sinclair, D. C. (1947). 'Pins and needles': observations on some of the sensations aroused in a limb by the application of pressure. Journal of Neurology, Neurosurgery, and Psychiatry, 10, 26-46.

Zotterman, Y. (1933). Studies in the peripheral nervous mechanism of pain. Acta Medica Scandinavica, 80, 185-242. 